\title{
Prognostic Impact of Diabetes Mellitus in Chronic Heart Failure According to Presence of Ischemic Heart Disease
}

\author{
- With Special Reference to Nephropathy -
}

Masanobu Miura, MD, PhD; Yasuhiko Sakata, MD, PhD; Satoshi Miyata, PhD;

Kotaro Nochioka, MD, PhD; Tsuyoshi Takada, MD, PhD; Soichiro Tadaki, MD; Ryoichi Ushigome, MD; Takeshi Yamauchi, MD; Kenjiro Sato, MD; Takeo Onose, MD; Kanako Tsuji, MD; Ruri Abe, MD; Jun Takahashi, MD, PhD; Hiroaki Shimokawa, MD, PhD on behalf of the CHART-2 Investigators

\begin{abstract}
Background: It is unclear whether the prognostic impact of diabetes mellitus (DM) in chronic heart failure (CHF) is influenced by ischemic heart disease (IHD) and/or nephropathy.

Methods and Results: We enrolled 4,065 consecutive patients with stage C/D CHF (mean age, 69.0 years; $68.7 \%$ male) in the CHART-2 Study $(n=10,219)$. We defined DM as current history of DM treatment or HbA1c $\geq 6.5 \%$ (National Glycohemoglobin Standardization Program [NGSP]), and nephropathy as urine albumin:creatinine ratio $\geq 30 \mathrm{mg} / \mathrm{g}$ or urine dipstick test $\geq( \pm)$ at enrollment. Impacts of DM and nephropathy on the composite of death, myocardial infarction, stroke, and HF admission were examined. Among the 4,065 patients, 1,448 (35.6\%) had DM, while IHD and nephropathy were also noted in 1,644 (40.4\%) and in 1,549 (38.1\%), respectively. During the median followup of 2.88 years, $1,025(25.2 \%)$ reached the composite endpoint. On multivariate Cox regression, DM was significantly associated with the composite endpoint in all patients (HR, 1.17; $\mathrm{P}=0.02)$, and in those with IHD (HR, 1.38; $\mathrm{P}=0.004)$, but not in those without IHD (HR, 1.12; $\mathrm{P}=0.22$; $\mathrm{P}$ for interaction=0.12). Furthermore, when the patients were stratified by nephropathy, DM was associated with worse prognosis only in the IHD patients with nephropathy.
\end{abstract}

Conclusions: The prognostic impact of DM was more evident in patients with IHD than in those without IHD, particularly when complicated with nephropathy. (Circ J 2015; 79: 1764-1772)

Key Words: Chronic heart failure; Diabetes; Ischemic heart disease; Nephropathy; Prognosis

D iabetes mellitus (DM) causes long-term complications, including microvascular (diabetic nephropathy, neuropathy and retinopathy $)^{1,2}$ and macrovascular complications, ${ }^{3}$ with resultant cardiovascular disease, stroke and peripheral arterial disease. The Framingham Heart Study showed that DM increases the risk of cardiovascular diseases such as acute myocardial infarction (AMI) and chronic heart failure $(\mathrm{CHF})^{4,5}$ Indeed, DM is a major health problem worldwide, including in patients with $\mathrm{CHF} .6,7$

\section{Editorial p1689}

In the general population, DM patients without ischemic heart disease (IHD) carry a lifetime risk of cardiovascular death as high as IHD patients without DM. ${ }^{8}$ In CHF patients, however, the prognostic impact of DM is still controversial. ${ }^{9-11}$ Several studies reported that DM was independently associated with increased mortality in CHF patients with IHD but not in those without it.9,10 In contrast, it was also reported that IHD was not the major prognostic factor in diabetic CHF patients. ${ }^{11}$ Also, diabetic nephropathy, usually defined as the presence of microalbuminuria $(30-300 \mathrm{mg} / \mathrm{g}$ urinary albumin:creatinine ratio [UACR]), has been reported as an important complication of DM. ${ }^{12}$ The prognostic impact of DM, however, remains unclear in CHF patients complicated by IHD and/or nephropathy.

In the present study, we thus examined the prognostic impact of DM with a special reference to IHD and nephropathy in CHF patients registered in the Chronic Heart failure Analysis and Registry in the Tohoku district 2 (CHART-2) Study. ${ }^{7,13-15}$

Received January 25, 2015; revised manuscript received March 28, 2015; accepted April 16, 2015; released online May 22, 2015 Time for primary review: 24 days

Department of Cardiovascular Medicine (M.M., Y.S., K.N., T.T., S.T., R.U., T.Y., K.S., T.O., K.T., R.A., J.T., H.S.), Department of Evidencebased Cardiovascular Medicine (S.M.), Tohoku University Graduate School of Medicine, Sendai, Japan

The Guest Editor for this article was Yoshihiko Saito, MD.

Mailing address: Yasuhiko Sakata, MD, PhD, Department of Cardiovascular Medicine, Tohoku University Graduate School of Medicine,

1-1 Seiryo-machi, Aoba-ku, Sendai 980-8574, Japan. E-mail: sakatayk@cardio.med.tohoku.ac.jp

ISSN-1346-9843 doi:10.1253/circj.CJ-15-0096

All rights are reserved to the Japanese Circulation Society. For permissions, please e-mail: cj@j-circ.or.jp 


\begin{tabular}{|c|c|c|c|c|}
\hline & \multirow{2}{*}{$\begin{array}{l}\text { All patients } \\
(n=4,065)\end{array}$} & \multicolumn{2}{|c|}{ DM } & \multirow{2}{*}{ P-value } \\
\hline & & $(+)(n=1,448)$ & $(-)(n=2,617)$ & \\
\hline Age (years) & $69.0 \pm 12.8$ & $68.3 \pm 11.3$ & $69.0 \pm 12.8$ & 0.10 \\
\hline Male (\%) & 68.7 & 72.0 & 66.8 & 0.001 \\
\hline History of admission for HF (\%) & 51.6 & 52.9 & 50.9 & 0.43 \\
\hline Ischemic heart disease (\%) & 40.4 & 51.0 & 34.6 & $<0.001$ \\
\hline \multicolumn{5}{|l|}{ Comorbidities (\%) } \\
\hline Hypertension & 78.2 & 83.8 & 75.1 & $<0.001$ \\
\hline Hyperuricemia & 45.8 & 46.1 & 45.6 & 0.77 \\
\hline Atrial fibrillation & 33.6 & 30.6 & 35.2 & 0.003 \\
\hline Cerebrovascular disease & 17.7 & 20.2 & 16.4 & 0.003 \\
\hline \multicolumn{5}{|l|}{ Clinical status } \\
\hline NYHA class 3-4 (\%) & 11.1 & 11.0 & 11.1 & 0.97 \\
\hline $\mathrm{BMI}\left(\mathrm{kg} / \mathrm{m}^{2}\right)$ & $23.4 \pm 3.8$ & $24.5 \pm 3.9$ & $23.4 \pm 3.8$ & $<0.001$ \\
\hline $\mathrm{SBP}(\mathrm{mmHg})$ & $126 \pm 19$ & $128 \pm 19$ & $126 \pm 19$ & 0.001 \\
\hline $\mathrm{DBP}(\mathrm{mmHg})$ & $72 \pm 12$ & $72 \pm 12$ & $72 \pm 12$ & 0.75 \\
\hline Heart rate (beats/min) & $72 \pm 15$ & $73 \pm 14$ & $72 \pm 15$ & 0.13 \\
\hline \multicolumn{5}{|l|}{ Laboratory data } \\
\hline LVEF (\%) & $57.5 \pm 15.3$ & $56.3 \pm 15.5$ & $57.5 \pm 15.3$ & 0.02 \\
\hline $\operatorname{LVDd}(\mathrm{mm})$ & $52.0 \pm 9.4$ & $52.3 \pm 9.1$ & $51.9 \pm 9.4$ & 0.19 \\
\hline Hemoglobin (g/dl) & $13.2 \pm 2.2$ & $13.2 \pm 2.2$ & $13.2 \pm 2.2$ & 0.88 \\
\hline BUN (mg/dl) & $19.3 \pm 8.8$ & $20.5 \pm 11.7$ & $19.3 \pm 8.8$ & $<0.001$ \\
\hline Serum sodium (mEq/L) & $141 \pm 2.8$ & $141 \pm 2.9$ & $141 \pm 2.8$ & $<0.001$ \\
\hline Serum potassium (mEq/L) & $4.3 \pm 0.4$ & $4.4 \pm 0.4$ & $4.3 \pm 0.4$ & 0.003 \\
\hline eGFR $\left(\mathrm{ml} / \mathrm{min} / 1.73 \mathrm{~m}^{2}\right)$ & $62.4 \pm 24.2$ & $60.5 \pm 21.3$ & $62.3 \pm 24.2$ & 0.01 \\
\hline $\mathrm{HbA} 1 \mathrm{c}(\%)$ & $5.8 \pm 0.4$ & $7.0 \pm 1.1$ & $5.8 \pm 0.4$ & $<0.001$ \\
\hline Nephropathy (\%) & 38.1 & 47.4 & 32.9 & $<0.001$ \\
\hline $\mathrm{BNP}(\mathrm{pg} / \mathrm{ml})$ & $100(41-229)$ & $98(39-220)$ & $101(42-233)$ & 0.65 \\
\hline \multicolumn{5}{|l|}{ Medications (\%) } \\
\hline RAS inhibitors & 73.2 & 73.5 & 73.1 & 0.77 \\
\hline$\beta$-blockers & 50.0 & 54.6 & 47.5 & $<0.001$ \\
\hline Aldosterone antagonists & 24.6 & 24.6 & 24.6 & 1.00 \\
\hline Loop diuretics & 46.7 & 48.8 & 45.6 & 0.05 \\
\hline Statins & 38.6 & 47.4 & 33.7 & $<0.001$ \\
\hline Anti-diabetic drugs & 15.6 & 43.8 & - & - \\
\hline Insulin & 4.1 & 11.5 & - & - \\
\hline \multicolumn{5}{|l|}{ Outcome (\%) } \\
\hline Composite endpoints & 25.2 & 27.1 & 24.1 & 0.04 \\
\hline
\end{tabular}

Continuous data given as mean $\pm \mathrm{SD}$, or median (IQR). BMI, body mass index; BNP, brain natriuretic peptide; BUN, blood urea nitrogen; CVD, cerebrovascular disease; DBP, diastolic blood pressure; DM, diabetes mellitus; eGFR, estimated glomerular filtration rate; HF, heart failure; LVDd, left ventricular end-diastolic diameter; LVEF, left ventricular ejection fraction; NYHA, New York Heart Association; RAS, renin-angiotensin system; SBP, systolic blood pressure.

\section{Methods}

\section{Subjects and Inclusion Criteria}

Details of the design, purpose, and basic characteristics of the CHART-2 Study have been described previously (NCT00418041)..$^{7,13-15}$ Briefly, the CHART-2 Study was started in October 2006 and we successfully enrolled 10,219 consecutive patients with stage $\mathrm{B} / \mathrm{C} / \mathrm{D}$ heart failure according to the ACCF/AHA guideline, ${ }^{16}$ or those with coronary artery disease by the end of March 2010. Among them, we examined 4,733 consecutive $\mathrm{CHF}$ patients with stage $\mathrm{C} / \mathrm{D} \mathrm{CHF}$ in the present study. We excluded 37 patients on hemodialysis, 382 without UACR or urine dipstick test (UDT) data, and 223 without sufficient data. Finally, we included 4,065 patients with stage $\mathrm{C} / \mathrm{D}$ CHF in the present study (Figure S1).
The study protocol was approved by the local ethics committee in the 24 participating hospitals and written informed consent was obtained from all patients. HF was diagnosed by experienced cardiologists using the criteria of the Framingham Heart Study.${ }^{17}$ IHD was defined by the presence of significant coronary artery disease with either organic stenosis requiring revascularization or vasospastic angina documented on electrocardiography or angiography. Hemoglobin A1c (HbA1c) was evaluated at the time of enrollment. We defined DM as history of anti-diabetic treatment and/or $\mathrm{HbA} 1 \mathrm{c} \geq 6.5 \%$ (National Glycohemoglobin Standardization Program [NGSP]). Estimated glomerular filtration rate (eGFR, $\mathrm{ml} / \mathrm{min} / 1.73 \mathrm{~m}^{2}$ ) was calculated using the modified modification of diet in renal disease equation with the Japanese coefficient ${ }^{18}$ at the time of enrollment. All data and events have been surveyed, and will con- 


\begin{tabular}{|c|c|c|c|c|c|c|}
\hline & \multicolumn{2}{|c|}{ IHD } & \multirow{2}{*}{ P-value } & \multicolumn{2}{|c|}{ Non-IHD } & \multirow{2}{*}{ P-value } \\
\hline & (+) DM (n=738) & $(-)$ DM (n=906) & & $(+)$ DM $(n=710)$ & $(-)$ DM $(n=1,711)$ & \\
\hline Age (years) & $69.0 \pm 10.3$ & $70.2 \pm 11.1$ & 0.04 & $67.8 \pm 12.1$ & $68.5 \pm 13.7$ & 0.18 \\
\hline Male (\%) & 79.5 & 79.1 & 0.85 & 64.1 & 60.3 & 0.09 \\
\hline History of admission for HF (\%) & 45.7 & 39.0 & 0.01 & 60.5 & 57.3 & 0.28 \\
\hline \multicolumn{7}{|l|}{ Comorbidities (\%) } \\
\hline Hypertension & 83.2 & 78.7 & 0.02 & 84.4 & 73.1 & $<0.001$ \\
\hline Hyperuricemia & 40.0 & 41.6 & 0.51 & 52.5 & 47.7 & 0.03 \\
\hline Atrial fibrillation & 16.3 & 15.8 & 0.79 & 45.5 & 45.5 & 1.00 \\
\hline Cerebrovascular disease & 20.4 & 17.1 & 0.10 & 20.0 & 16.0 & 0.02 \\
\hline \multicolumn{7}{|l|}{ Clinical status } \\
\hline NYHA class 3-4 (\%) & 10.0 & 9.7 & 0.75 & 12.0 & 12.0 & 0.54 \\
\hline $\operatorname{BMI}\left(\mathrm{kg} / \mathrm{m}^{2}\right)$ & $24.6 \pm 3.6$ & $23.8 \pm 3.3$ & 0.001 & $24.3 \pm 4.8$ & $22.8 \pm 5.1$ & $<0.001$ \\
\hline $\mathrm{SBP}(\mathrm{mmHg})$ & $129 \pm 19$ & $127 \pm 18$ & 0.04 & $127 \pm 20$ & $125 \pm 19$ & 0.02 \\
\hline $\mathrm{DBP}(\mathrm{mmHg})$ & $72 \pm 11$ & $73 \pm 11$ & 0.03 & $73 \pm 13$ & $72 \pm 13$ & 0.32 \\
\hline Heart rate (beats/min) & $71 \pm 13$ & $70 \pm 13$ & 0.34 & $74 \pm 15$ & $73 \pm 16$ & 0.04 \\
\hline \multicolumn{7}{|l|}{ Laboratory data } \\
\hline $\operatorname{LVEF}(\%)$ & $55.7 \pm 14.9$ & $56.8 \pm 14.8$ & 0.16 & $56.9 \pm 16.1$ & $57.8 \pm 15.7$ & 0.25 \\
\hline LVDd (mm) & $52.8 \pm 8.7$ & $52.1 \pm 8.4$ & 0.06 & $51.7 \pm 9.5$ & $51.9 \pm 9.9$ & 0.69 \\
\hline Hemoglobin (g/dl) & $13.3 \pm 2.2$ & $13.3 \pm 2.2$ & 0.41 & $13.2 \pm 2.1$ & $13.2 \pm 2.2$ & 0.88 \\
\hline BUN (mg/dl) & $19.9 \pm 12.0$ & $18.4 \pm 7.4$ & 0.001 & $21.1 \pm 11.3$ & $19.9 \pm 9.6$ & 0.01 \\
\hline Serum sodium (mEq/L) & $141 \pm 2.8$ & $141 \pm 2.7$ & $<0.001$ & $141 \pm 2.9$ & $141 \pm 2.9$ & 0.007 \\
\hline Serum potassium (mEq/L) & $4.4 \pm 0.4$ & $4.3 \pm 0.4$ & 0.71 & $4.4 \pm 0.5$ & $4.3 \pm 0.5$ & $<0.001$ \\
\hline eGFR $\left(\mathrm{ml} / \mathrm{min} / 1.73 \mathrm{~m}^{2}\right)$ & $60.5 \pm 20.7$ & $61.5 \pm 18.8$ & 0.08 & $60.2 \pm 22.1$ & $62.7 \pm 26.6$ & 0.01 \\
\hline $\mathrm{HbA} 1 \mathrm{c}(\%)$ & $7.1 \pm 1.1$ & $5.8 \pm 0.3$ & $<0.001$ & $7.0 \pm 1.0$ & $5.8 \pm 0.4$ & $<0.001$ \\
\hline Nephropathy (\%) & 47.3 & 30.4 & $<0.001$ & 48.0 & 34.8 & $<0.001$ \\
\hline BNP (pg/ml) & $114(45-246)$ & $85(33-191)$ & 0.04 & $116(46-256)$ & $121(51-258)$ & 0.34 \\
\hline \multicolumn{7}{|l|}{ Medications (\%) } \\
\hline RAS inhibitors & 69.8 & 73.6 & 0.09 & 77.5 & 72.8 & 0.02 \\
\hline$\beta$-blockers & 50.4 & 45.1 & 0.04 & 59.0 & 48.7 & $<0.001$ \\
\hline Loop diuretics & 39.2 & 29.9 & $<0.001$ & 58.7 & 53.9 & 0.03 \\
\hline Statins & 62.2 & 60.8 & 0.58 & 32.0 & 19.3 & $<0.001$ \\
\hline Aldosterone antagonists & 17.9 & 16.3 & 0.43 & 31.5 & 29.0 & 0.22 \\
\hline Anti-diabetic drugs & 49.6 & - & - & 37.7 & - & - \\
\hline Insulin & 13.6 & - & - & 9.3 & - & - \\
\hline
\end{tabular}

Continuous data given as mean \pm SD, or median (IQR). IHD, ischemic heart disease. Other abbreviations as in Table 1.

tinue to be surveyed at least once a year until the end of March $2018 .^{7,13-15}$

\section{Microalbuminuria}

Albuminuria was evaluated quantitatively using UACR or qualitatively on UDT. ${ }^{12}$ Urine samples were collected at outpatient clinics or during hospitalization but before discharge. Urine albumin was measured in a central laboratory (SRL, Tokyo, Japan) to calculate UACR. UDT was performed in each hospital, and we defined positive UDT for microalbuminuria as $\geq$ trace. $^{19}$

\section{Outcomes}

The primary outcome of the present study was the composite endpoint of death, AMI, HF admission and stroke. Mode of death was determined by the attending physician at each institution and was confirmed by one independent physician who was a member of the Tohoku Heart Failure Association. ${ }^{7}$

\section{Statistical Analysis}

Statistical analysis was performed for the total group, those with IHD and those without IHD. We utilized Kaplan-Meier curves and Cox proportional hazard models to compare the risk for composite endpoint of DM with regard to IHD or nephropathy. We constructed the Cox proportional hazard models adjusted by the following covariates that could potentially influence outcome: age, sex, NYHA class, systolic blood pressure, heart rate, hyperlipidemia, hyperuricemia, body mass index (BMI), serum hemoglobin, eGFR, blood urea nitrogen (BUN), serum sodium, atrial fibrillation, left ventricular ejection fraction (LVEF), history of HF admission and cerebrovascular disease, and medications (renin-angiotensin system [RAS] inhibitors, $\beta$-blockers, aldosterone antagonists and statins). Comparison of categorical variables between the 2 groups was done using chi-squared test. Continuous variables are described as mean \pm SD and discrete data as $\%$. Brain natriuretic peptide (BNP) is described as median (IQR) because of the skewness of the distribution. Statistical analysis was performed using SPSS Statistics 21.0 (SPSS, Chicago, IL, USA) and R 3.1.2. ${ }^{20}$ Statistical significance was defined as 2 -sided $\mathrm{P}<0.05$. 

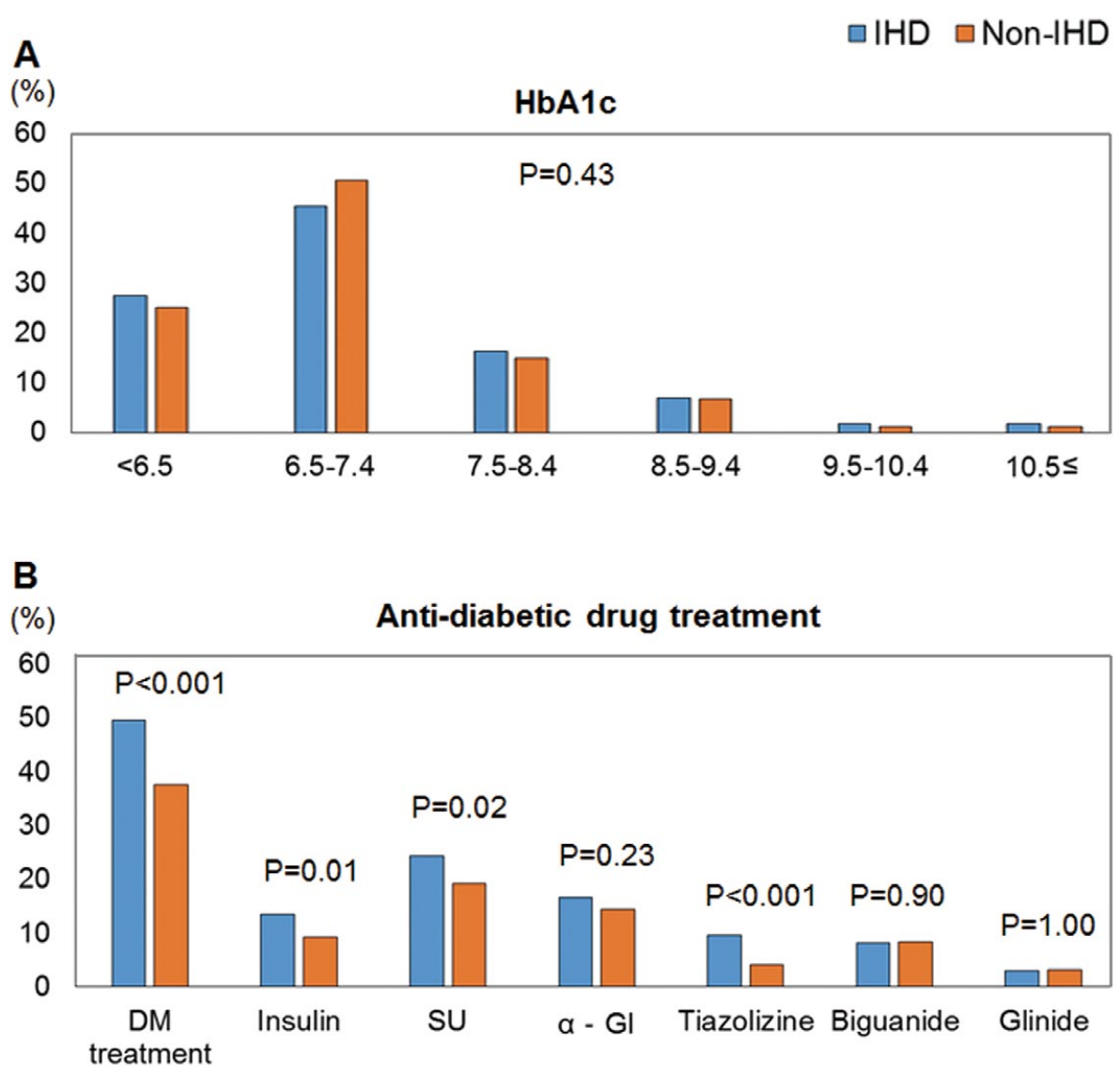

Figure 1. Distribution of (A) HbA1c and (B) anti-diabetic drug treatment in patients with diabetes mellitus (DM). $a$-Gl, $a$-glucosidase inhibitor; IHD, ischemic heart disease; SU, sulfonylurea.

\section{Baseline Characteristics}

\section{Results}

Table 1 lists the baseline patient characteristics. Mean age was 69.0 years and male patients accounted for $68.7 \%$. Cause of CHF was classified as IHD in $40.4 \%$, and mean LVEF and HbA1c were $57.5 \pm 15.3 \%$ and $5.8 \pm 0.4 \%$, respectively. In IHD patients, $68.4 \%$ and $20.6 \%$ of them underwent percutaneous coronary intervention and coronary artery bypass grafting, respectively. The prevalence of DM and of nephropathy was $35.6 \%$ and $38.1 \%$, respectively. The patients with DM, as compared with non-DM patients, were characterized by higher prevalence of male sex, IHD, nephropathy, history of hypertension and of cerebrovascular disease, and higher BMI and BUN. Mean HbA1c in the DM patients was $7.0 \pm 1.1 \%$. Forty-seven per cent of DM patients had received anti-diabetic drug treatment at the time of enrollment.

Table 2 lists the patient baseline characteristics according to presence of IHD and DM. Diabetic IHD patients, as compared with non-diabetic IHD patients, had a higher prevalence of prior $\mathrm{HF}$ admission and hypertension and were characterized by higher BMI, BUN and BNP. Mean HbA1c in the diabetic IHD patients was $7.1 \pm 1.1 \%$. Diabetic non-IHD patients were also likely to have a history of hypertension and cerebrovascular disease, and were characterized by higher BMI and
BUN, compared with non-DM non-IHD patients. Mean HbA1c in the DM patients was similar between patients with and without IHD (7.1 $\pm 1.1 \%$ vs. $7.0 \pm 1.0 \%, P=0.08$; Figure 1A). Diabetic non-IHD patients, however, were less likely to have had antidiabetic drug treatment compared with diabetic IHD patients (37.7\% vs. $49.6 \%, \mathrm{P}<0.001$; Figure 1B). Sulfonylurea, insulin and $\alpha$-glucosidase inhibitors were frequently used in both diabetic IHD and diabetic non-IHD patients (Figure 1B).

\section{Prognostic Impact of DM}

During the median follow-up period of 2.88 years, the composite endpoint occurred in 1,025 patients $(25.2 \%)$. As compared with the non-diabetic patients, the diabetic patients had significantly poorer prognosis (Figure 2A). Table 3 lists the results of multivariate Cox proportional hazard regression models for the composite endpoint. As compared with the nondiabetic patients (reference), diabetic patients had a 1.17-fold higher risk for the composite endpoint $(\mathrm{P}=0.03)$. When the patients were stratified according to IHD, non-diabetic IHD patients had the best prognosis (Figure 2B). Compared with non-diabetic IHD patients (reference), diabetic IHD, nondiabetic non-IHD, and diabetic non-IHD patients had worse prognosis with HR (95\% confidence interval [95\% CI]) of 1.39 (1.14-1.69), 1.38 (1.12-1.71) and 1.55 (1.24-1.93), respectively (Figure 2B). 

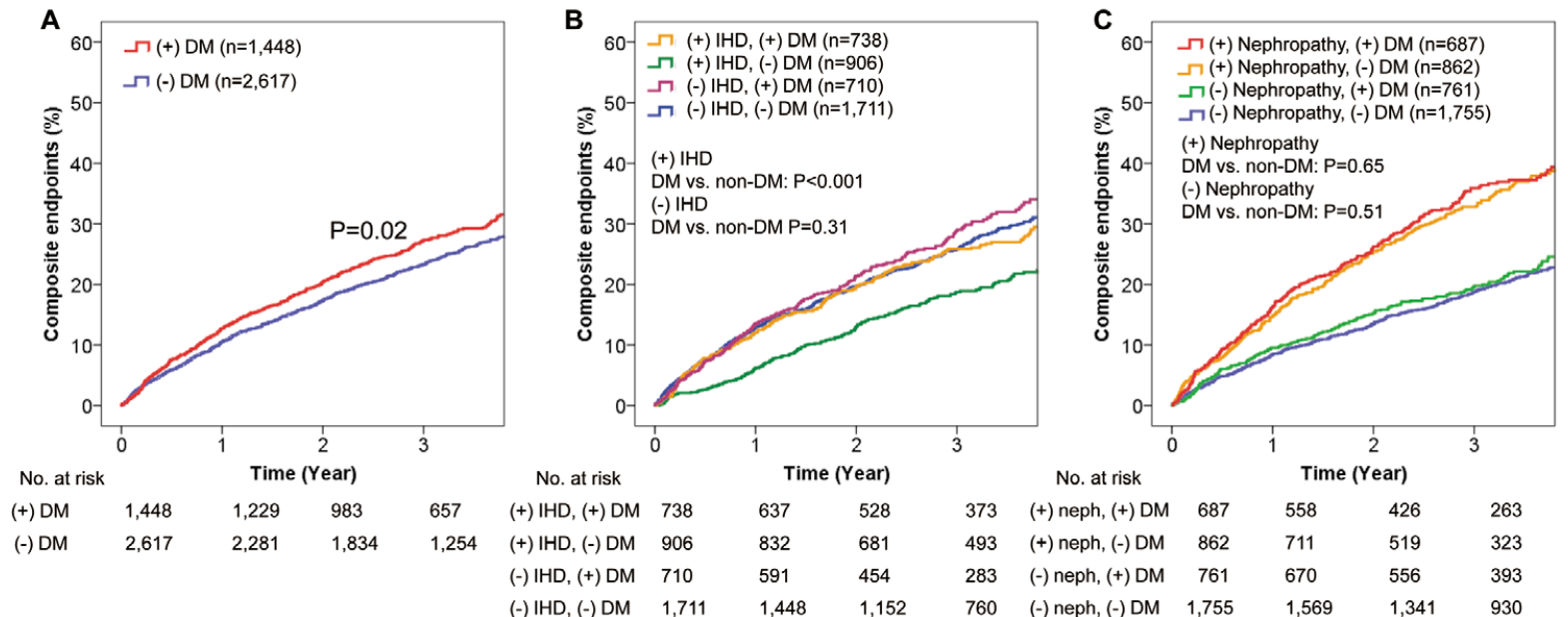

Figure 2. Kaplan-Meier curves for the composite endpoint stratified by (A) diabetes mellitus (DM); (B) DM and ischemic heart disease (IHD); and (C) DM and nephropathy (neph).

\begin{tabular}{|c|c|c|c|}
\hline \multirow[t]{2}{*}{ HR categories } & \multicolumn{3}{|c|}{ All patients $(n=4,065)$} \\
\hline & HR & $95 \% \mathrm{Cl}$ & P-value \\
\hline \multicolumn{4}{|l|}{ Univariate } \\
\hline (-) DM & 1.00 & & \\
\hline (+) DM & 1.16 & $1.02-1.32$ & 0.02 \\
\hline \multicolumn{4}{|l|}{ Multivariate } \\
\hline$(-)$ DM & 1.00 & & \\
\hline (+) DM & 1.17 & $1.01-1.34$ & 0.03 \\
\hline (+) IHD, (-) DM & 1.00 & & \\
\hline (-) IHD, (-) DM & 1.39 & $1.14-1.69$ & 0.001 \\
\hline (+) IHD, (+) DM & 1.38 & $1.12-1.71$ & 0.003 \\
\hline (-) IHD, (+) DM & 1.55 & $1.24-1.93$ & $<0.001$ \\
\hline (-) Nephropathy, (-) DM & 1.00 & & \\
\hline (-) Nephropathy, (+) DM & 1.14 & $0.94-1.38$ & 0.20 \\
\hline (+) Nephropathy, (-) DM & 1.67 & $1.42-1.97$ & $<0.001$ \\
\hline (+) Nephropathy, (+) DM & 1.80 & $1.51-2.15$ & $<0.001$ \\
\hline
\end{tabular}

$\mathrm{Cl}$, confidence interval; $\mathrm{HR}$, hazard ratio. Other abbreviations as in Tables 1,2.

We further examined the prognostic impact of DM with regard to nephropathy. We found that diabetic patients had an increased incidence of the composite endpoint only when associated with nephropathy (Figure 2C). The patients with nephropathy had poorer prognosis regardless of the presence or absence of DM. Among the IHD patients, diabetic patients with nephropathy had the poorest outcome (Figure 3A). On multivariate Cox modeling, adjusted HR (95\% CI) in diabetic patients without nephropathy, non-diabetic patients with nephropathy and diabetic patients with nephropathy was $1.08(0.78-1.49), 1.56$ (1.14-2.14) and 2.36 (1.77-3.15), respectively, as compared with non-diabetic patients without nephropathy (Table 4). In contrast, among the non-IHD patients, those with nephropathy had significantly poorer prognosis regardless of the presence or absence of DM (Figure 3B; Table 4). When complicated with both DM and nephropathy, IHD patients had a significant and positive interaction ( $\mathrm{P}$ for interaction $=0.006$ ) for the composite endpoint $(\mathrm{HR}=2.36, \mathrm{P}<0.001)$, as compared with the nonIHD patients (HR, 1.50; $\mathrm{P}=0.001)$. Among the IHD patients, diabetic patients with nephropathy had the highest incidence of all-cause death, cardiovascular death, HF admission and stroke (Figure 4). In contrast, among the non-IHD patients, the incidences of all-cause death, cardiovascular death and HF admission were increased only when associated with nephropathy but not with DM (Figure 4).

\section{Discussion}

The novel findings of the present study are that (1) among stage C/D CHF patients, DM is significantly associated with worse prognosis, especially when complicated by IHD; (2) among CHF patients with IHD, DM is associated with worse prognosis only when complicated by nephropathy; and (3) the prognostic impact of DM is significantly higher in IHD patients than in non-IHD patients when complicated by nephropathy. These findings underline the clinical importance of nephropathy in the management of diabetic CHF patients, especially in those with IHD, in real-world practice.

\section{DM in CHF Patients}

In the present study, DM was significantly associated with worse prognosis, especially in the patients with IHD. Although similar findings were reported in the subgroup analysis of the previous clinical trials of $\mathrm{HF}, 9,10$ the present study has confirmed these observations for the first time in a cohort study. The present study also found that the prognostic impact of DM was different between IHD and non-IHD patients. In the general population, diabetic patients have a similar cardiovascular risk to those with IHD, ${ }^{8}$ but it remains controversial as to whether the prognostic impact of DM differs between IHD and non-IHD in patients with CHF. ${ }^{9-11}$ In the present study, diabetic patients with IHD tended to be associated with worse prognosis as compared with those without IHD (P for interaction=0.12). Although HbAlc was similar between IHD and 


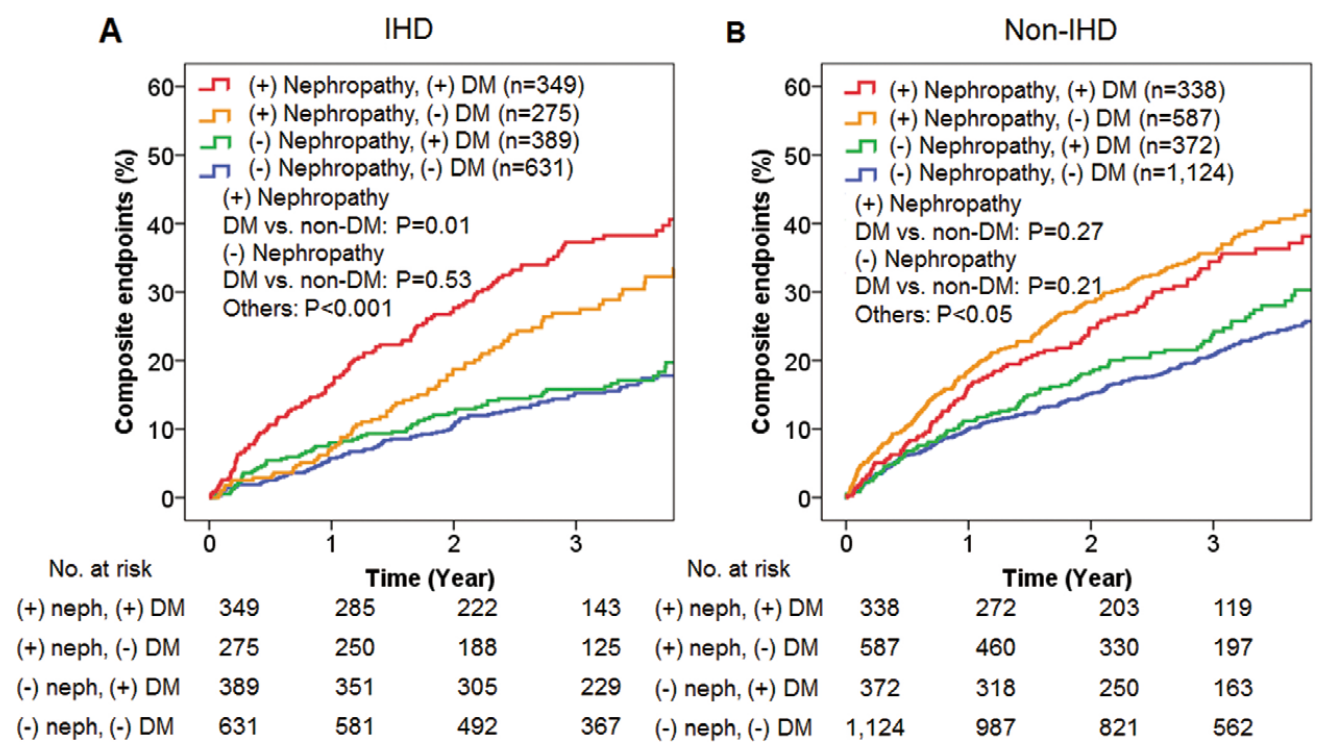

Figure 3. Kaplan-Meier curves for the composite endpoint for diabetes mellitus (DM) and nephropathy (neph) in patients (A) with and (B) without ischemic heart disease (IHD).

\begin{tabular}{|c|c|c|c|c|c|c|c|}
\hline \multirow{2}{*}{ HR categories } & \multicolumn{3}{|c|}{ CHF with IHD $(n=1,785)$} & \multicolumn{3}{|c|}{ CHF without IHD $(n=2,503)$} & \multirow{2}{*}{$\begin{array}{c}P \text { for } \\
\text { interaction }\end{array}$} \\
\hline & HR & $95 \% \mathrm{Cl}$ & P-value & HR & $95 \% \mathrm{CI}$ & P-value & \\
\hline$(-) \mathrm{DM}$ & 1.00 & & & 1.00 & & & \\
\hline (+) DM & 1.38 & $1.11-1.71$ & 0.004 & 1.12 & $0.94-1.33$ & 0.22 & 0.12 \\
\hline (-) Nephropathy & 1.00 & & & & & & \\
\hline (+) Nephropathy & 1.89 & $1.49-2.32$ & $<0.001$ & 1.52 & $1.29-1.80$ & $<0.001$ & 0.09 \\
\hline (-) Nephropathy, (-) DM & 1.00 & & & 1.00 & & & \\
\hline (-) Nephropathy, (+) DM & 1.08 & $0.78-1.49$ & 0.64 & 1.26 & $0.98-1.61$ & 0.07 & 0.13 \\
\hline (+) Nephropathy, (-) DM & 1.56 & $1.14-2.14$ & 0.005 & 1.69 & $1.40-2.06$ & $<0.001$ & 0.73 \\
\hline (+) Nephropathy, (+) DM & 2.36 & $1.77-3.15$ & $<0.001$ & 1.50 & $1.18-1.91$ & 0.001 & 0.006 \\
\hline
\end{tabular}

The model was adjusted for age, sex, NYHA class, SBP, heart rate, hyperlipidemia, hyperuricemia, BMI, hemoglobin, eGFR, BUN, serum sodium, atrial fibrillation, LVEF, history of HF admission and cerebrovascular disease, and medication (RAS inhibitors, $\beta$-blockers, statins and aldosterone antagonists). CHF, chronic HF. Other abbreviations as in Tables 1-3.

non-IHD patients, diabetic patients with IHD were more likely to receive anti-diabetic drugs than those without IHD. Thus, the duration and severity of DM could be different between IHD and non-IHD patients, which may have caused the different prognostic impact of DM between IHD and non-IHD patients.

\section{Importance of Nephropathy}

$\mathrm{HbA} 1 \mathrm{c}$ concentration is widely used for routine monitoring of mid-term glycemic status, response to therapy and risk assessment for DM complications. ${ }^{21}$ Although HbA1c reflects the summed glycemic level for the past several months, it frequently fluctuates according to glycemic level and/or anti-diabetic treatment. Thus, the usefulness of HbA1c for risk stratification in CHF patients remains uncertain. ${ }^{22,23}$ For this reason, we investigated the possible importance of nephropathy, one of the important comorbidities of DM and CHF.,2,24 When complicated with both DM and nephropathy, IHD patients had significant and positive interaction for the composite endpoint as compared with non-IHD patients. In general, CHF patients with microalbuminuria have poorer prognosis regardless of DM, hypertension or renal function, given that microalbuminuria is likely to be associated with inflammation and activation of the RAS and sympathetic nervous system. ${ }^{24}$ This could explain why, in the present study, IHD patients with both DM and nephropathy had more cardiovascular events. In contrast, in the absence of nephropathy, DM patients had a similar prognosis to nonDM patients. Thus, among CHF patients with IHD, DM has a prognostic impact only when complicated by nephropathy.

In contrast, among the non-IHD patients, nephropathy was significantly associated with poorer prognosis regardless of the presence or absence of DM. The severity of CHF, in terms of NYHA class and BNP level, was higher in non-IHD patients than in IHD patients without nephropathy. Given that microalbuminuria is known to reflect increased intravascular volume with resultant edema, ${ }^{25}$ it is conceivable that the presence of nephropathy may reflect the severity of HF and general condition in CHF patients without IHD. 


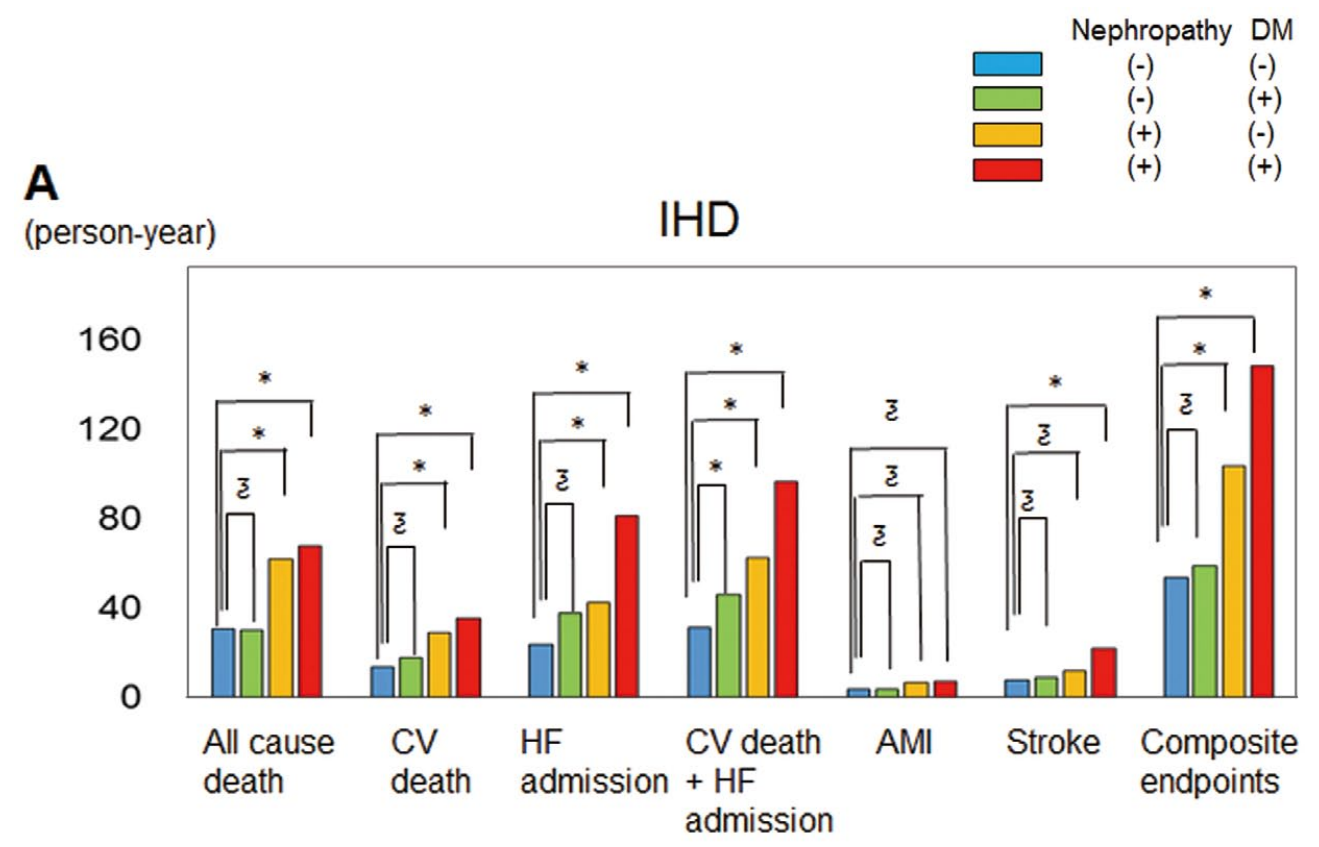

B

(person-year)

Non-IHD

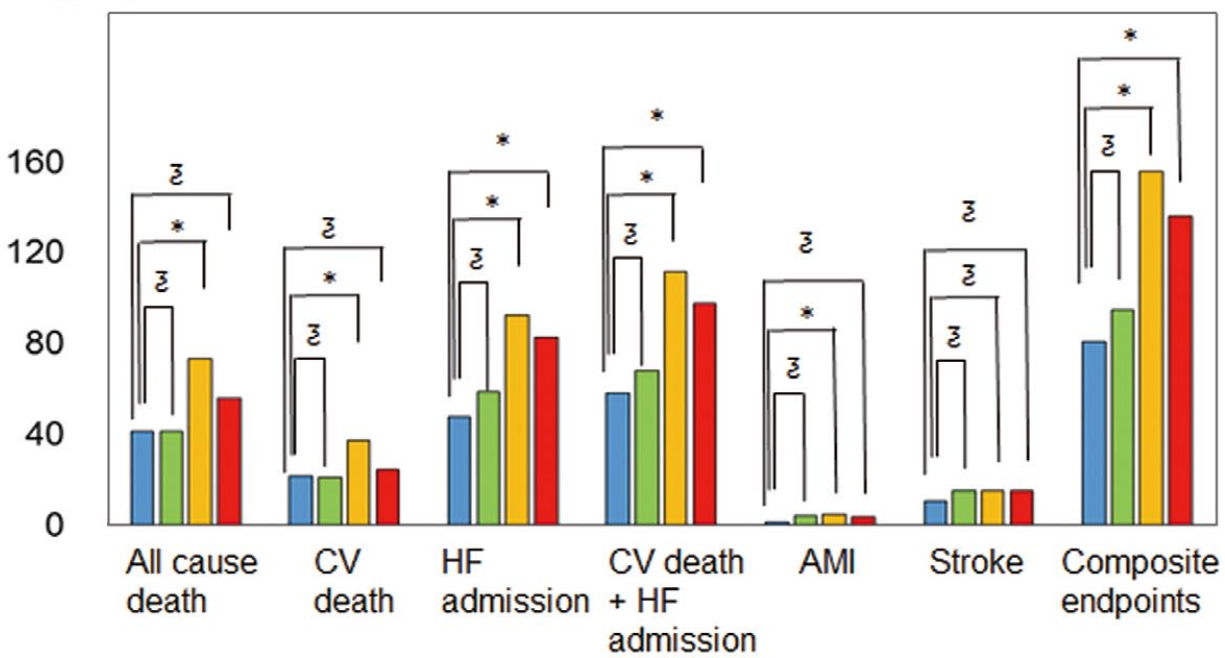

Figure 4. Incidence of cardiovascular (CV) endpoints in patients (A) with and (B) without ischemic heart disease (IHD). AMI, acute myocardial infarction; DM, diabetes mellitus; $\mathrm{HF}$, heart failure. ${ }^{\xi} \mathrm{P}=\mathrm{NS}$. ${ }^{\star} \mathrm{P}<0.05$.

Reduced eGFR is an important risk factor for mortality in CHF patients. ${ }^{26}$ In the clinical setting, however, eGFR is calculated using age, sex and serum creatinine. Thus, GFR does not necessarily reflect the extent of renal damage. Indeed, according to the current classification of chronic kidney disease, microalbuminuria, a sensitive indicator of renal damage, is defined as a risk factor even if GFR is preserved. ${ }^{12}$ Furthermore, the revised classification of diabetic nephropathy was focused on the importance of the presence of microalbuminuria, especially in patients with preserved or mildly reduced GFR. ${ }^{27}$ Thus, nephropathy should be evaluated using albuminuria for risk stratification especially in patients with preserved or mildly reduced GFR.
Management of DM With Regard to Nephropathy in CHF

In the present study, the DM control status was relatively better than in previous studies. ${ }^{28,29} \mathrm{DM}$, however, was significantly associated with worse prognosis in CHF patients, especially in those with nephropathy. Reduction in HbA1c using anti-diabetic drugs (eg, insulin and sulfonylurea) is linked to improved renal function. ${ }^{30,31}$ In the present study, HbA1c control status in the DM CHF patients with IHD was similar to that in the intensive treatment groups in those previous studies. ${ }^{30,31}$ In the present study, however, $>40 \%$ of patients had nephropathy, a significant predictor of worsening prognosis. Thus, renal protection strategy should be established for diabetic CHF patients, especially when complicated by IHD. Further studies are warranted 
to examine the possible beneficial effects of new anti-diabetics such as dipeptidyl peptidase- 4 inhibitors on both renal and cardiovascular protection. ${ }^{32}$

\section{Study Limitations}

Several limitations should be mentioned for the present study. First, measurement of albuminuria was performed indirectly using either UACR or UDT. ${ }^{12}$ It has been reported, however, that trace proteinuria evaluated on UDT could be a useful indicator of microalbuminuria in subjects at high risk for cardiovascular disease.${ }^{19}$ Furthermore, a recent study showed that trace UDT could identify microalbuminuria with a high specificity and negative predictive value. ${ }^{33}$ Thus, we consider that the bias of the present method, if any, would be minimal in the detection of microalbuminuria. Second, we did not have sufficient information to explain the cause of nephropathy in each patient. Thus, we were unable to define nephropathy in DM patients as diabetic nephropathy in the present study. Third, we did not have sufficient information on management history of DM at enrollment. Thus, it remains to be elucidated whether the difference in the management of DM influenced the present results. Fourth, in the present study, the data collected at the time of enrollment were analyzed and we did not take into consideration the possible changes in albuminuria during the follow-up period. Fifth, given that all subjects in the CHART-2 Study were Japanese patients, caution should be taken when extrapolating the present findings to patients in other countries. Finally, given that the CHART-2 Study is an observational study, there might be unmeasured confounding factors that could have influenced the present results.

\section{Conclusions}

The prognostic impact of DM is more evident in CHF patients with IHD than in those without IHD, particularly when complicated by nephropathy. Thus, the clinical importance of nephropathy should be underlined in the management of DM in the real-world practice of CHF, although further studies are needed to confirm the present results.

\section{Acknowledgments}

We thank all members of the Tohoku Heart Failure Society and the staff of the Departments of Cardiovascular Medicine and Evidence-Based Cardiovascular Medicine for their kind contributions (Supplementary File 1). This study was supported in part by Grants-in-Aid from the Ministry of Health, Labour, and Welfare and the Ministry of Education, Culture, Sports, Science, and Technology, Japan.

\section{Conflicts of Interest}

The Department of Evidence-based Cardiovascular Medicine, Tohoku University Graduate School of Medicine, is supported in part by unrestricted research grants from Daiichi Sankyo (Tokyo, Japan), Bayer Yakuhin (Osaka, Japan), Kyowa Hakko Kirin (Tokyo, Japan), Kowa Pharmaceutical (Tokyo, Japan), Novartis Pharma (Tokyo, Japan), Dainippon Sumitomo Pharma (Osaka, Japan), and Nippon Boehringer Ingelheim (Tokyo, Japan). H.S. has received lecture fees from Bayer Yakuhin (Osaka, Japan), Daiichi Sankyo (Tokyo, Japan) and Novartis Pharma (Tokyo, Japan).

\section{References}

1. UK Prospective Diabetes Study Group. Intensive blood glucose control with sulphonylureas or insulin compared with conventional treatment and risk of complications in patients with type 2 diabetes (UKPDS 33). Lancet 1998; 352: 837-853.

2. Keenan HA, Costacou T, Sun JK, Doria A, Cavellerano J, Coney J, et al. Clinical factors associated with resistance to microvascular complications in diabetic patients of extreme disease duration: The 50-year medalist study. Diabetes Care 2007; 30: 1995-1997.
3. Almdal T, Scharling H, Jensen JS, Vestergaard H. The independent effect of type 2 diabetes mellitus on ischemic heart disease, stroke, and death: A population-based study of 13,000 men and women with 20 years of follow-up. Arch Intern Med 2004; 164: 1422 - 1426.

4. Kannel WB, McGee DL. Diabetes and cardiovascular disease: The Framingham study. JAMA 1979; 241: 2035-2038.

5. Kannel WB, Hjortland M, Castelli WP. Role of diabetes in congestive heart failure: The Framingham study. Am J Cardiol 1974; 34: $29-34$.

6. King H, Aubert RE, Herman WH. Global burden of diabetes, 19952025: Prevalence, numerical estimates, and projections. Diabetes Care 1998; 21: 1414-1431.

7. Shiba N, Nochioka K, Miura M, Kohno H, Shimokawa H; CHART-2 Investigators. Trend of westernization of etiology and clinical characteristics of heart failure patients in Japan: First report from the CHART-2 study. Circ J 2011; 75: 823-833.

8. Whiteley L, Padmanabhan S, Hole D, Isles C. Should diabetes be considered a coronary heart disease risk equivalent?: Results from 25 years of follow-up in the Renfrew and Paisley survey. Diabetes Care 2005; 28: $1588-1593$.

9. Dries DL, Sweitzer NK, Drazner MH, Stevenson LW, Gersh BJ. Prognostic impact of diabetes mellitus in patients with heart failure according to the etiology of left ventricular systolic dysfunction. $J$ Am Coll Cardiol 2001; 38: 421-428.

10. Domanski M, Krause-Steinrauf H, Deedwania P, Follmann D, Ghali JK, Gilbert E, et al. The effect of diabetes on outcomes of patients with advanced heart failure in the BEST trial. J Am Coll Cardiol 2003; 42: 914-922.

11. Andersson C, Weeke P, Pecini R, Kjaergaard J, Hassager C, Køber $\mathrm{L}$, et al. Long-term impact of diabetes in patients hospitalized with ischemic and non-ischemic heart failure. Scand Cardiovasc J 2010; 44: $37-44$.

12. Kidney Disease: Improving Global Outcomes (KDIGO) CKD Work Group. KDIGO clinical practice guideline for the evaluation and management of chronic kidney disease. Kidney Int Suppl 2013; 3: $1-150$.

13. Miura M, Shiba N, Nochioka K, Takada T, Takahashi J, Kohno H, et al. Urinary albumin excretion in heart failure with preserved ejection fraction: An interim analysis of the CHART 2 study. Eur J Heart Fail 2012; 14: 367-376.

14. Miura M, Sakata Y, Nochioka K, Takada T, Tadaki S, Ushigome R, et al. Prevalence, predictors and prognosis of patients with heart failure requiring nursing care. Circ J 2014; 78: 2276-2283.

15. Miura M, Sakata Y, Miyata S, Nochioka K, Takada T, Tadaki S, et al. Prognostic impact of subclinical microalbuminuria in patients with chronic heart failure. Circ J 2014; 78: 2890-2898.

16. Yancy CW, Jessup M, Bozkurt B, Butler J, Casey DE Jr, Drazner MH, et al; American College of Cardiology Foundation; American Heart Association Task Force on Practice Guidelines. 2013 ACCF/AHA guideline for the management of heart failure: Executive summary: A report of the American College of Cardiology Foundation/American Heart Association Task Force on practice guidelines. Circulation 2013; 128: e240-e327, doi:10.1161/CIR.0b013e31829e8807.

17. McKee PA, Castelli WP, McNamara PM, Kannel WB. The natural history of congestive heart failure: The Framingham study. $N$ Engl $J$ Med 1971; 285: 1441-1146.

18. Imai E, Horio M, Nitta K, Yamagata K, Iseki K, Hara S, et al. Estimation of glomerular filtration rate by the MDRD study equation modified for Japanese patients with chronic kidney disease. Clin Exp Nephrol 2007; 11: 41-50.

19. Konta T, Hao Z, Takasaki S, Abiko H, Ishikawa M, Takahashi T, et al. Clinical utility of trace proteinuria for microalbuminuria screening in the general population. Clin Exp Nephrol 2007; 11: 51-55.

20. R Core Team. R: A language and environment for statistical computing. Vienna: R Foundation for Statistical Computing, 2012.

21. Rohlfing CL, Wiedmeyer HM, Little RR, England JD, Tennill A, Goldstein DE. Defining the relationship between plasma glucose and $\mathrm{HbA}(1 \mathrm{c})$ : Analysis of glucose profiles and $\mathrm{HbA}(1 \mathrm{c})$ in the Diabetes Control and Complications Trial. Diabetes Care 2002; 25: 275-278.

22. Erqou S, Lee CT, Suffoletto M, Echouffo-Tcheugui JB, de Boer RA, van Melle JP, et al. Association between glycated haemoglobin and the risk of congestive heart failure in diabetes mellitus: Systematic review and meta-analysis. Eur J Heart Fail 2013; 15: 185- 193.

23. Aguilar D, Bozkurt B, Ramasubbu K, Deswal A. Relationship of hemoglobin A1C and mortality in heart failure patients with diabetes. J Am Coll Cardiol 2009; 54: 422-428.

24. Jackson CE, Solomon SD, Gerstein HC, Zetterstrand S, Olofsson B, Michelson EL, et al. Albuminuria in chronic heart failure: Prevalence and prognostic importance. Lancet 2009; 374: 543-550.

25. Lieb W, Mayer B, Stritzke J, Doering A, Hense HW, Loewel H, et 
al. Association of low-grade urinary albumin excretion with left ventricular hypertrophy in the general population: The MONICA/KORA Augsburg Echocardiographic Substudy. Nephrol Dial Transplant 2006; 21: 2780-2787.

26. Shiba N, Matsuki M, Takahashi J, Tada T, Watanabe J, Shimokawa H. Prognostic importance of chronic kidney disease in Japanese patients with chronic heart failure. Circ J 2008; 72: 173-178.

27. Haneda M, Utsunomiya K, Koya D, Babazono T, Moriya T, Makino $\mathrm{H}$, et al. A new classification of diabetic nephropathy 2014: A report from Joint Committee on Diabetic Nephropathy. Clin Exp Nephrol 2015; 19: $1-5$.

28. Lind M, Bounias I, Olsson M, Gudbjörnsdottir S, Svensson AM, Rosengren A. Glycaemic control and incidence of heart failure in 20,985 patients with type 1 diabetes: An observational study. Lancet 2011; 378: $140-146$

29. Gerstein HC, Pogue J, Mann JF, Lonn E, Dagenais GR, McQueen $\mathrm{M}$, et al. The relationship between dysglycaemia and cardiovascular and renal risk in diabetic and non-diabetic participants in the HOPE study: A prospective epidemiological analysis. Diabetologia 2005; 48: $1749-1755$.

30. Stratton IM, Adler AI, Neil HA, Matthews DR, Manley SE, Cull CA, et al. Association of glycaemia with macrovascular and microvascu- lar complications of type 2 diabetes (UKPDS 35): Prospective observational study. $B M J$ 2000; 321: 405-412.

31. Duckworth W, Abraira C, Moritz T, Reda D, Emanuele N, Reaven $\mathrm{PD}$, et al. Glucose control and vascular complications in veterans with type 2 diabetes. $N$ Engl J Med 2009; 360: 129-139.

32. Satoh-Asahara N, Sasaki Y, Wada H, Tochiya M, Iguchi A, Nakagawachi R, et al. A dipeptidyl peptidase-4 inhibitor, sitagliptin, exerts anti-inflammatory effects in type 2 diabetic patients. Metabolism 2013; 62: 347-351.

33. White SL, Yu R, Craig JC, Polkinghorne KR, Atkins RC, Chadban SJ. Diagnostic accuracy of urine dipsticks for detection of albuminuria in the general community. Am J Kidney Dis 2011; 58: 19-28.

\section{Supplementary Files}

Supplementary File 1

Figure S1. Study flow.

CHART-2 Study Investigators

Please find supplementary file(s); http://dx.doi.org/10.1253/circj.CJ-15-0096 